\title{
Red Cross volunteers' experience with a mobile community event- based surveillance (CEBS) system in Sierra Leone during-and after the Ebola outbreak- A qualitative study
}

\author{
Tine Mejdell Larsen ${ }^{1}$, Christina Brux Mburu ${ }^{1}$, Anine Kongelf ${ }^{2}$, Tonje Tingberg ${ }^{2}$, Fatmata Sannoh ${ }^{3}$ and Ahmed Madar ${ }^{*}$ \\ ${ }^{1}$ Department of Community Medicine, Institute of Health and Society, University of Oslo, Norway \\ ${ }^{2}$ Disaster Management Unit, International Department, Norwegian Red Cross, Oslo, Norway \\ ${ }^{3}$ Sierra Leone Red Cross and Red Crescent Society, Freetown, Sierra Leone
}

\begin{abstract}
Purpose: The objective of this study was to explore the volunteers' experiences with and perspectives on the community event-based surveillance system in Sierra Leone.

Methods and materials: 62 volunteers from 14 different chiefdoms participated in in-depth interviews and focus group discussions, which were audio recorded and transcribed. A comprehensive and systematic thematic analysis was conducted, which identified key benefits and challenges.

Results: The volunteers believe CEBS positively impacts their communities. CEBS increases knowledge and behavior change, contributing to the prevention of Ebola and other diseases and decreasing overall mortality. Volunteers are motivated to participate by an aspiration of helping their community, although many volunteers also participated in the hope of receiving monetary incentives. Communities were initially reluctant to participate in surveillance due to fear of Ebola, but acceptance increased with improved community engagement. Reporting by phone call and SMS was perceived as a quick and simple way of reporting, although challenges with access to mobile network, sim registration and cost for charging were identified. Many of the volunteers could not repeat or explain the different case definitions and explained reporting on symptoms solely or other health events, suggesting that the volunteers did not have a clear understanding of case definitions or purpose of CEBS.
\end{abstract}

Conclusion: SMS reporting directly from the community is perceived as a timely, easy and reliable way of sharing important information, but the usefulness of the system relies not only on the structure of the system itself, but also on external factors, such as the relationship between the community members and the volunteers, and the logistical structure.

\begin{abstract}
Abbreviations:
CBS-community-based surveillance; CBVcommunity-based volunteer; CEBS-community event-based surveillance; $\mathrm{CHO}$-community health officer; $\mathrm{CHW}$-community health worker; FGD-focus group discussion; IFRC-International Federation of Red Cross and Red Crescent Societies; RC-Red Cross; PHU-peripheral health unit; SLRCS -Sierra Leone Red Cross Society; SOP-standard operating procedure; VHF-viral haemorrhagic fever; VSS-volunteer surveillance supervisor
\end{abstract}

\section{Background}

The role of mobile technology and community- based surveillance

In many resource-poor countries in which epidemics are most likely to break out, there is often limited systematic disease surveillance, or the surveillance systems are only facility-based $[1,2]$, even though access to health facilities is scarce. In these contexts, communitybased surveillance (CBS) could be a vital strategy for early warning and response. CBS is an active surveillance process that is simple, adaptable, and entails community participation in detecting, reporting, responding to and monitoring health events in the community [3-5]. Mobile technology is also increasingly used in CBS. Having people from the communities reporting by phone is seen as a potentially efficient way of collecting early data directly from the communities, depending on access to mobile network. With over 6 billion mobile phone subscribers and $75 \%$ of the world having access to mobile phones, there is an opportunity for using mobile phones to improve access to health care, engagement and delivery of health services, as well as health outcomes [6].

Few studies about CBS have been published, especially with the use of mobile phones. A systematic review of mobile health surveillance interventions in Sub-Saharan Africa [7] concludes that the interventions that have been implemented are small-scale, fragmented and not well documented. The authors encourage more research on the subject, especially about user acceptance, in addition to better documentation of lessons learned, as they believe CBS with real-time and validated data will strengthen disease monitoring. Tomlinson, et al. [8] also found a

Correspondence to: Ahmed Madar, Department of Community Medicine, Institute of Health and Society, University of Oslo, Kirkeveien 166 Fredrik Holsts hus 0450 OSLO, Norway, Tel: +47-22850634; E-mail: a.a.madar@medisin.uio.no

Key words: Community, health, $m$ Health, surveillance, SMS, volunteerism

Received: August 16, 2017; Accepted: September 08, 2017; Published: September 12, 2017 
Larsen TM (2017) Red Cross volunteers' experience with a mobile community event- based surveillance (CEBS) system in Sierra Leone during-and after the Ebola outbreak- A qualitative study

limited number of published studies about using mobile phones as a data collection tool, but concluded through their own study that collecting data through mobile phones was feasible on a large scale and that it provided timely data, no loss of data and continuous supervision of the reporters. This is also supported by Hartzler, et al. [9]. Other studies have documented the importance of involving the community. Diwan, et al. [10] reported enormous underreporting of infectious diseases in India, as most people went to local, informal health services that were not part of the regular surveillance system in the country.

\section{Ebola virus outbreak in Sierra Leone 2014-2015 and the role of community event based surveillance (CEBS)}

Sierra Leone was one of the three West African countries most severely affected by the Ebola virus outbreak, which started in Guinea in December 2013 and then spread to Liberia and Sierra Leone. The World Health Organization(WHO) declared the outbreak an international concern in August 2014, and pronounced it as officially over in March 2016 [11]. During the outbreak, Sierra Leone had 14,124 cases and 3956 deaths confirmed to have been caused by the Ebola virus [12]. Several factors delayed the detection, diagnosing and isolation of patients, hence enabling rapid spreading of the outbreak, which created a complicated and unique context for controlling it [13].

Many areas in Sierra Leone are hard to reach and have limited access to health facilities. In addition to this, fear and distrust in the health facilities increased during the outbreak [14], and an increasing number of infected persons remained in their communities until they died [15], as so-called "superspreaders" causing a high number of secondary cases [16].

Community event-based surveillance (CEBS) was designed by a consortium of non-governmental organizations (NGOs) which made up the Ebola Response Consortium (ERC). CEBS was intended as an active, community-level surveillance system for Ebola Virus Disease (EVD), with community members using mobile phones to call with reports of suspected EVD cases [17]. This information fed into the formal surveillance system at the peripheral health units (PHUs) and district-level surveillance office through the District Ebola Response Centre (DERC). The initiative was led and coordinated by the Ministry of Health and Sanitation (MoHS). It was implemented through ERC partners in 9 districts, and the International Federation of Red Cross and Red Crescent (IFRC) and Sierra Leone Red Cross society (SLRCS) (hereafter 'Red Cross') in 3 districts, providing coverage in 12 out of 14 districts [18].

As weekly numbers of Ebola cases declined in the first quarter of 2015, Red Cross started a process of aligning CEBS with the SLRCS recovery strategy and activity plan. The standard operating procedure (SOP) for CEBS developed by the ERC was used [17], but SLRCS' CEBS project was expanded to target the detection and reporting of cases of viral haemorrhagic fevers (VHF), including Ebola and Lassa fever; acute watery diarrhoea (AWD) as a proxy for cholera; measles and community deaths. CEBS was integrated into the SLRCS's existing community-based health program (CBHP) and disaster risk reduction (DRR) plan. Hence, the CEBS reporting also included floods and fire. Whilst the main objective of CEBS is early warning for epidemic-prone diseases, data collection on the prevalence of these six community events can also contribute to guiding community-based interventions and long-term programs as vulnerabilities are revealed [19]. In this case, data collection through SMS was also added. The system was implemented in the three districts; Port Loko, Koinadugu and Bonthe, beginning in Port Loko in July 2015.
SLRCS volunteers, both community- based volunteers and volunteer supervisors were recruited from their communities and trained in the purpose of CEBS, signs and symptoms of the chosen events and diseases, how to report the cases by SMS to SLRCS headquarter, and trained in the stages of the surveillance from the detection of the cases to the reporting, the verification and the response. The volunteers were expected to be active in their community; inform the community about signs and symptoms and encourage the community members to report to the volunteer if they-or anyone they knew experienced any of these. The volunteers reported the suspected cases including which sign or symptom that was observed and which measures had been taken at community level, and supported the national health authorities in the response.

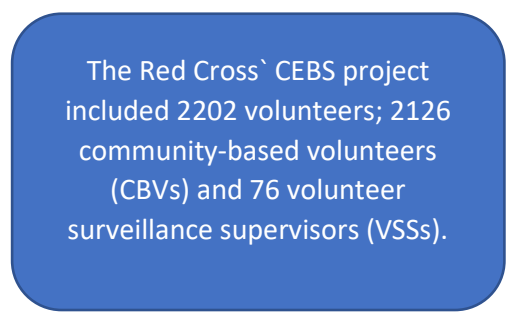

As Port Loko was experiencing a high number of cases in July, CEBS was rapidly implemented without the SMS report feature and entailed reporting on only suspected Ebola cases. Reporting was done via phone call when a suspected case was detected and weekly paper reporting forms collected by the supervisors (Figure 1).

When a suspected case is identified, the CBVs call and report to their VSS. If the VSS evaluate the case to match case definition, s/he contacts the CHO- a local health authority staff, and they assess the suspected case together. The $\mathrm{CHO}$ is the only one who can diagnose and who will report further in the national health system to initiate a response to the suspected case.

The CBV and VSS send an individual coded SMS right after alerting and responding with different information for data collection (19], The SMS is sent to a local number which is synced with the online data collection tool, Magpi [20) via the application SMSsync [21). The information is then automatically combined and presented in the analytical visualizing database, Tableau [22,23]. Currently, Tableau presents the volunteer coverage in the area, cases reported; what type of case, gender, age, location, response and if it was escalated to the

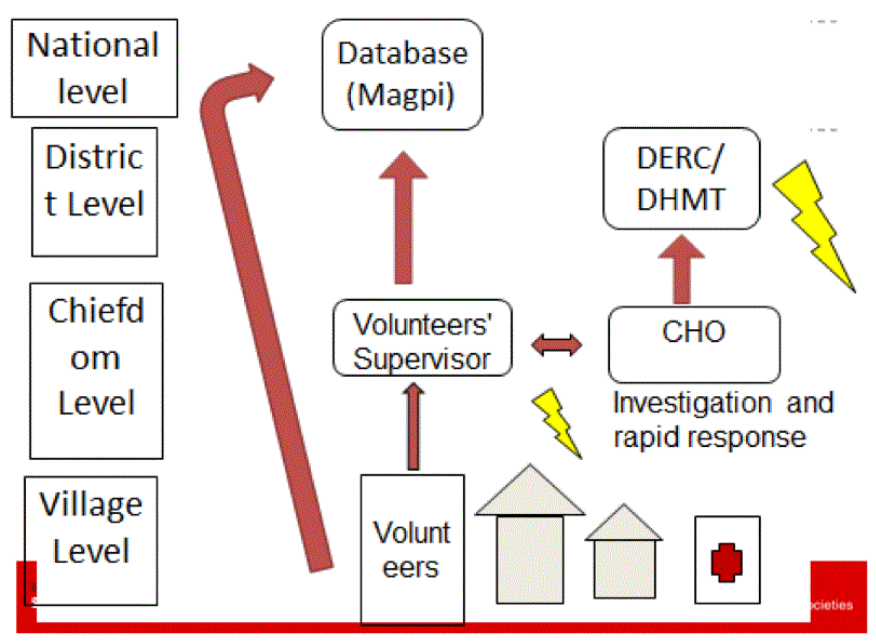

Figure 1. Reporting flow. 
district health management team. SLRCS is responsible for community engagement, detection and reporting of suspected cases to the national health facilities, while the health facilities are responsible for the response to the suspected case (Table 1 and 2).

\section{Methodology}

The objective of this study was to explore the volunteers' experiences with using the CEBS system, and perspectives on how CEBS influences the communities in Sierra Leone. We selected a qualitative study design. The flexibility inherent in this exploratory, qualitative design provided important possibilities to engage in preliminary analytical reflections while in the field, identifying emerging themes and adjusting the data collection accordingly.

\section{Setting}

The study was conducted in the three districts of Sierra Leone where the Red Cross implemented CEBS; Port Loko, Koinadugu and Bonthe (Figure 2).

\section{Participant recruitment and study sample}

We chose a purposive method when selecting the volunteers, with the aim of recruiting both male and female volunteers with a wide age-

\section{Table 1. SMS code}

\begin{tabular}{|l|l|l|l|}
\hline Volunteer Surveillance Supervisors code & Community- Based Volunteers code \\
\hline Type of Event & Reporting Code & Type of Event & Reporting Code \\
\hline Suspected EVD & 1 & Suspected EVD & 1 \\
\hline $\begin{array}{l}\text { Acute Watery } \\
\text { Diarrhea }\end{array}$ & 2 & $\begin{array}{l}\text { Acute Watery } \\
\text { Diarrhea }\end{array}$ & 2 \\
\hline Measles & 3 & Measles & 3 \\
\hline Community Death & 4 & Community Death & 4 \\
\hline Flood & 5 & Flood & 5 \\
\hline Wild Fire & 6 & Wild Fire & 6 \\
\hline Escalation & & Gender & \\
\hline Yes & 1 & Male & 1 \\
\hline No & 0 & Female & 2 \\
\hline & No person affected & 0 \\
\hline Chiefdom level response & 0 & Age & \\
\hline None & 1 & Age in years & Number of years \\
\hline Assessment by phone & 1 & No person affected & 0 \\
\hline $\begin{array}{l}\text { Investigation / visit } \\
\text { to community }\end{array}$ & 2 & \multicolumn{2}{|l|}{} \\
\hline $\begin{array}{l}\text { Referral to PHU / } \\
\text { Hospital }\end{array}$ & 3 & & \\
\hline
\end{tabular}

Table 2. Examples of SMS reports.

\begin{tabular}{|c|c|c|}
\hline & $\begin{array}{l}\text { Volunteer Surveillance } \\
\text { Supervisors SMS }\end{array}$ & $\begin{array}{l}\text { Community- Based } \\
\text { Volunteers SMS }\end{array}$ \\
\hline Explanation & $\begin{array}{l}000 \text { \# volunteer's phone } \\
\text { number \# type of event \# } \\
\text { escalation \# response. }\end{array}$ & $\begin{array}{l}444 \text { \# type of event \# gender } \\
\text { \# age. }\end{array}$ \\
\hline \multirow[t]{2}{*}{ Example } & $\begin{array}{l}\text { If a volunteer has reported } \\
\text { a person who suffers from } \\
\text { acute watery diarrhea, } \\
\text { and you have visited the } \\
\text { community, notified DHMT } \\
\text { (escalation), and encouraged } \\
\text { the person to go to the clinic } \\
\text { report like this: } \\
000 \text { \# } 23279219228 \# 2 \# \\
1 \# 3\end{array}$ & $\begin{array}{l}\text { If the volunteer has detected } \\
\text { a person who suffers from } \\
\text { acute watery diarrhea, and } \\
\text { this person is a } 15 \text { year old } \\
\text { male, the report is written } \\
\text { like this: } \\
444 \# 2 \text { \# } 1 \text { \# } 15\end{array}$ \\
\hline & & $\begin{array}{l}\text { If there are no events } \\
\text { to be reported from the } \\
\text { community, send a ZERO } \\
\text { report like this } \\
444 \text { \# } 0 \text { \# } 0 \text { \# } 0\end{array}$ \\
\hline
\end{tabular}

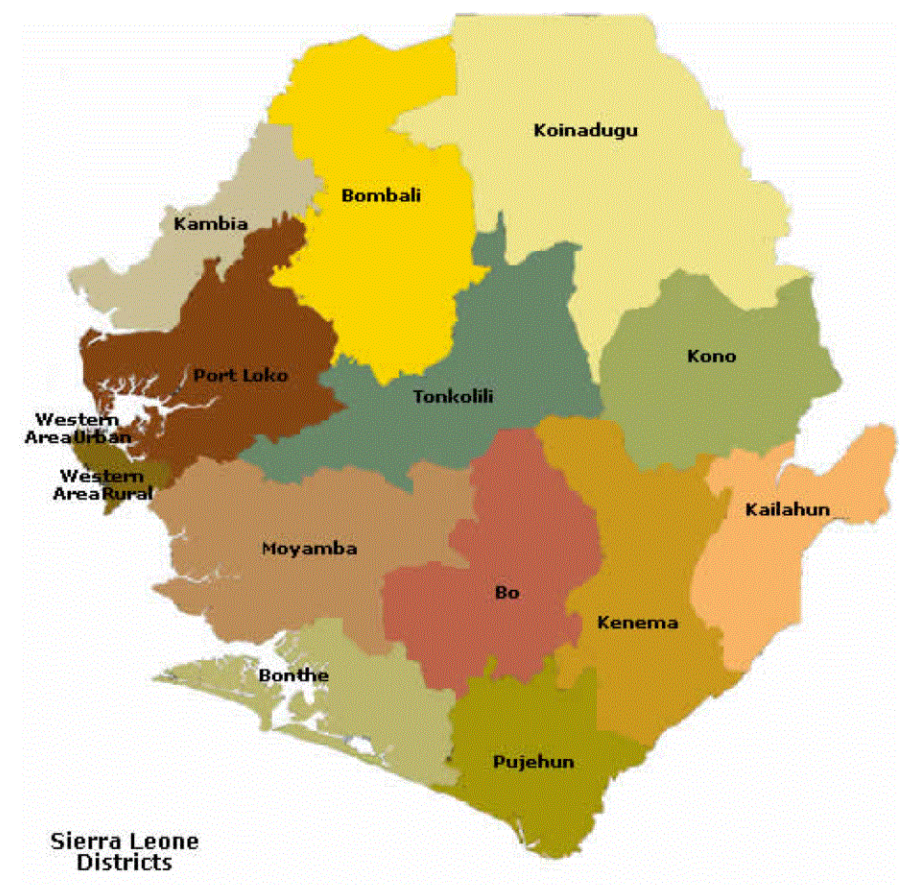

Figure 2. District map over Sierra Leone [23].

range and from a variety of communities to achieve a diverse sample and to understand if potential difference in reporting or in experience was linked to the system itself or factors in the communities. The VSSs were recruited from CEBS supervisor meetings, and supervisors from different chiefdoms, which differed in size, terrain and number of CBVs, were asked to participate in FGDs. For the community-based volunteers, volunteers from different chiefdoms were either called by the research assistant or approached in the community they lived and volunteered in. There was a requirement that the volunteers spoke English and that they lived in or close to a community that could be reached by car, with the exception of Bonthe district, where all the participants from Bonthe Island travelled to as there is no access with car beyond the main town.

Sixty-two volunteers participated in the study; the age range was from 20-45 years old and the participants were students, teachers, farmers, bakers, IT workers, barbers, volunteers who had previously worked for other organizations and some who were unemployed. It was not possible to obtain an even gender distribution in the participant sample. This reflects the fact that $85 \%$ of all CBVs and all VSSs, except two, were male. A total of seven female participants were included in this study's sample.

\section{Data collection}

Data was collected during a 4-week period in December 2015 and January 2016.

Twenty-two in-depth interviews were conducted with 22 community-based volunteers (CBVs) from 14 different chiefdoms. Five FGDs were conducted, two with CBVs and three with volunteer surveillance supervisors (VSSs). Eight volunteers participated in each FGD. A semi-structured, thematic guide was used for the interviews and the FGDs were structured via broad, open-ended questions. The FGDs and interviews were audio-recorded and transcribed, and observations, notes and reflections were written down by the main author and, at times, by the research assistant, who was present as an observer during 
Larsen TM (2017) Red Cross volunteers' experience with a mobile community event- based surveillance (CEBS) system in Sierra Leone during-and after the Ebola outbreak- A qualitative study

some of the interviews and FGDs. The audio recordings were later transcribed for analysis purposes.

Conversational data collection via in-depth interviews and focus group discussions (FGDs) was well-suited to the research objective of exploring experiences, perceptions and perspectives. The in-depth interviews presented opportunities for exploring the details of personal experience and pursuing in-depth understandings of individual perspectives, while the FGDs facilitated understanding of the range of perspectives and perceptions present among the volunteers, highlighting important differences and similarities, and producing insight into not only what was said, but also the interactions between them.

\section{Data analysis}

Initial, preliminary analyses took place already while in the field, for the sake of reflecting on the data collection as it took place and identifying and exploring emerging themes. Once data collection was complete, a comprehensive, systematic thematic analysis [24] was performed using the software HyperRESEARCH. The data set was thematically coded, explored and analyzed, ultimately resulting in 6 main thematic groups that shed light on the volunteers' perceptions of and experiences with CEBS (Table 3 ).

\section{Approvals}

Regional Committees for Medical and Health Research Ethics (REC) determined that this project was not mandated by the Act on Medical and Health Research and could be conducted without their approval. The project was then reported to the Norwegian Centre for Research Data (NSD) and was approved in 2015. Sierra Leone Ethics and Scientific Review Committee approved the study in, 2015.

\section{Results and discussion}

\section{Volunteers' motivation}

When the volunteers were asked about what motivated them to volunteer, they all, in different ways, replied that they want to help their communities, and felt that CEBS was an important way to do so (Table 4):

"I want to work for CEBS cause I feel for my fellow human beings."

"If we had CEBS before, Ebola would not have spread so much."

Most volunteers gave examples of cases they had reported which had received response and treatment. Many of the volunteers were confident that the death rate had decreased due to CEBS influencing people to seek medical attention earlier.

Additionally, incentives and the possibility for paid work were discussed as motivations. Several of the volunteers gave examples of other Red Cross programs and INGOs that they had worked for or knew of that pay the volunteers monthly incentives. This suggests that the volunteers might hope for or even expect to receive incentives, and that this could also have been a motivating factor to volunteer.

As seen in a previous study conducted among community health workers in Ghana [25], the volunteers did not want to specify an exact

Table 3. Final groups after coding.

Volunteer motivation and support

Recruitement and distribution of volunteers

Training and preparedness

Reporting methods

Reporting structure and indicators

Collaboration and community acceptance
Table 4. Key findings.

\section{Key findings}

Positive finding:

- CEBS perceived as an easy and rapid way of reporting

- Volunteers are motivated by a desire to support their communities

- The volunteers report increased knowledge among themselves and in the communities

- Volunteer surveillance supervisors (VSSs) have an important support function

- Guidelines are perceived as an important support during the reporting

- The volunteers felt prepared after the training, and after the practical training, in particular

- The volunteers belong to the communities from which they report

- The volunteers report less fear of and increased use of the health facilities Challenges:

- Distance between communities

- Variation in the number of CBVs the VSSs are responsible for

- Volunteers hope for and sometimes expect incentives

- Uncertainties around how to send the SMS and what and why to report

- Poor mobile network coverage in many areas

- Delays in registration of sim cards and credit

- Diseases regarded important and relevant by the community are not included in CEBS

- High expectations from the community due to high need for health services

- Fear from some community members due to fear of Ebola

amount and explained that the amount is not important as long as they received something to support their family or expenses they had with CEBS, or even to help in the community. One CBV, who had spent money on transportation to a CEBS meeting, asked:

"Why would I use the money I have for raising my child on meetings?"

The volunteers discussed their interest in receiving support for their families and communities, and receiving reimbursement for expenses interchangeably. This could mean that, for the volunteers, the lines between these are blurred, but it could also mean that this is more comfortable than directly asking for incentives.

In the end of this discussion, some of the volunteers explained that they had asked if they would receive payment during the training, and that when they asked about this during the training, they were told that this would be discussed later, leaving them expecting to receive something. Some of the volunteers seemed very irritated and would raise their voice when talking about this.

A study from Mexico [26] describes verbal appreciation and social events as some of the most valued incentives. Another study from Uganda, looking at motivation among CHWs and influence on performance [27], describes acknowledgement by and appreciation from the community, and thus feeling important, as motivating. Although none of the CBVs from the CEBS study specifically said that these were incentives they valued, they often described supportive visits from the VSSs, appreciation from the PHU, community health officers and community leaders, and community gratitude as CEBS was gaining acceptance and producing positive results. They talked about this with visible pride, suggesting that acknowledgement from the community and their supervisors is an important motivation:

"Yeah, I feel good because my supervisor reaches me many times and asks me about work. 'How is the work?' He asks if I have trouble anywhere."

\section{Volunteer recruitment and coverage}

"Another challenge is that the villages are more than the CEBS volunteers. Like, for one chiefdom, we have 60 villages, but 20 something volunteers. So, some volunteers are assigned several villages. So, to go there, we are finding it hard. To every day have to go to all the villages, to go between 3 villages two times in the week to check, it is difficult. It 
will take time. You will not have time to go to your family, to find food for your family."

Many of the volunteers were assigned several communities and found this difficult due to the distances between them. Recruiting more volunteers was a recurrent suggestion. On the other hand, supervisors found it challenging to follow up many CBVs. As CBS is implemented to report from the communities to make it easy, it might work against its purpose to not have volunteers present in all communities, but then there might be a need to also increase the number of VSSs or adapt the way information is coming from the communities. This should be considered according to context when implementing CBS. As with a study conducted in Niger, the community members received basic education to motivate them to notify health workers about possible cases in a timely matter [28]. Some of the CBVs also described alternative solutions to address the heavy workload, like organizing sub-groups of community members and agreements with community leaders to report rumors.

\section{Training}

The volunteers say there was a lack of knowledge about diseases, disasters and prevention in the communities before CEBS, and, regardless of what information the volunteers found most useful from the training, they all appreciated receiving new knowledge for themselves and which they could share with their communities. The practical methods like role-play, working with illustrations and the practical training for sending the SMS, was said to be most useful.

"People have phones, but they have them to have coverage and to call their friends and family. But text message is another indicator, because you have to click, click, click and look for the different images, like the hash. You have so many difficulties. It is going and click and going this way. That's why a training needs many days, or a refreshr training, so people can understand."

The wish for refresher training was something that was brought up often during the interviews and FGDs. Some CBVs also explained how they arrange refresher trainings amongst themselves to help each other with how to write the SMS reports, but they wanted a more organized refresher training. As a CBS should predominantly report on suspected diseases that occur infrequently, refresher trainings are likely necessary for both maintaining the knowledge and following up and motivating the volunteers by coming together, learning and giving feedback. The need for sufficient training is supported by a study conducted in Ghana [29] were the CHWs receive minimum refresher training and thus were unable to report according to case definitions.

\section{Case definitions}

Some of the volunteers focused on individual symptoms more than the combination of symptoms that comprised the case definition. This could be because they actually did not remember the indicators, did not understand the case definition, could not visualize the disease represented by it, or wanted to include more cases.

Despite reporting on symptoms, the SMS codes still limit what they can report. This was supported by seeing that in Port Loko, which did not use coded SMS reporting, the volunteers reported far more cases that were not relevant to the decided case definitions. The volunteers express frustration about being limited to reporting only those cases prioritized by CEBS, as they find it difficult to reject community members who want them to report other symptoms for them to get help. This suggests that the function of SMS codes work as a filter and sustains the purpose of the CEBS system as early warning surveillance instead of a regular disease reporting system. On the other hand, perhaps using case definitions can be too complicated, and a solution is to report rumors for unusual events, as done in Ethiopia [30].

Some of the volunteers could not pronounce VHF and did not know that Ebola is one form of VHF, but thought it was a different disease. On the other hand, it was also described by the volunteers how the community members were scared when they used the word Ebola, and they thought that's why VHF was used instead.

"Maybe the name we say to people, we have to be careful. When you talk about Ebola, people got fear, so to transform it, it's called VHF (Laughing). People are scared of Ebola. Whenever you talk about Ebola people run away and say "they want to kill us again”. But, if you say VHF, they will come closer. So, from there, from the signs and symptoms, we will see if this is Ebola and we will report, but we cannot say 'Ebola' “(laughing again).

These findings suggest that the formulation of the case definition used is an important aspect to consider, as it may have significance far beyond the words used to describe a disease. Creating the case definitions together with representatives from the communities could be a way of ensuring that they are context specific. A study done in South Africa piloted their survey questions with women from the local communities before conducting it [8]. This is something that should be considered for case definitions before implementing CBS.

\section{Collaboration with the community members}

Some of the volunteers explained that, in the beginning, talking about Ebola in the community was very sensitive because most of the people had difficult and even traumatic experiences with Ebola, and they would express anger towards the volunteers. In these situations, the volunteers said that they took their time to explain CEBS to the community members. Because the volunteers were from the communities themselves, people eventually started trusting and listening to them. On the other hand, many of the volunteers also described that the community members appreciated them greatly and had high expectations to what the volunteers could help them with, as many lived far from health facilities or still had fear directed towards health facilities.

"I think community people are appreciating it so much. Knowing that they have people around them who protect them and look out for them, they feel safe."

Some of the volunteers, both CBV and VSS are community health workers $(\mathrm{CHW})$ and normally work with the peripheral health unit (PHU). Many of these volunteers had difficulty explaining who they were reporting to and what they were reporting as they have a long list of diseases they should report from the community to the PHU, including the suspected diseases CEBS was reporting. Some said that they would report some cases to the PHU first, but if there was a CEBS case, they would call the VSS, but this also depended on the severity of the case. The volunteers expressed confusion around this, which suggest that CEBS could potentially create a duplicate system that either led to duplication of reports or missing reports, as there seemed to be confusion about who to report to. Some of the volunteers also said they would call their VSS about all sick cases in their community even if they did not send an SMS about them. This led to the question of whether the community members were addressing the volunteer as a CEBS volunteer or a CHW. One of the volunteers who was also a $\mathrm{CHW}$ explained that he would treat some people in the community for some diseases he was allowed to treat. This is not the mandate for the CEBS 
volunteers as they are not meant to diagnose or treat, but report to the CHO. This can pose challenges for the Red Cross volunteers who are not CHWs but might nonetheless be expected to act as such by the community members. On the other hand, many of the volunteers said that they did not have CHWs in their community, indicating that the existing CHW system was not covering all areas. This suggests that there is a need for CEBS, but that recruiting CHWs could complicate the role of the volunteers.

\section{Volunteer work combined with paid work}

Although many of the volunteers said it was difficult to combine CEBS volunteering with ordinary, paid work, they also said that they wanted CEBS to continue and they want to continue volunteering. The volunteers said they had an important role for the health of their people and nation. Many of the volunteers said that they choose to prioritize the volunteer work over ordinary work, although the reality might be that they, regardless of CEBS volunteering or not, lack paid work opportunities and potentially expect or hope for incentives. “ $\mathrm{M} \mathrm{o} \mathrm{s} \mathrm{t}$ of us were not doing anything. Some left to work for RC, not because we were expecting money, but now looking at the whole process as a supervisor, there is no way for me - waiting for an alert 24 hours a day - cause that's what we are told - $24 \mathrm{hrs}$, we should be ready for alerts. How can I be engaged in something else? Let's say that I was engaged in organization B and the volunteer called me and I was working somewhere else. How could I go there? I cannot. I don 't think CEBS would be very effective. So, we all choose to only stay with CEBS."

As supported in the study by Ndiaye et al. (28), including CBS in existing projects can be important to both engage the communities, but also for sustainability and to ensure volunteers do not perceive it as a stand- alone project with other expectations and requirements than the regular volunteer programs. As in Sierra Leone, where there was a need for full coverage quickly, this is not always possible, but should be something to consider when planning implementation.

\section{External challenges}

The volunteers had some challenges regarding the use of mobile phones, due to lack of mobile network in all areas and delays in registration of sim card. When discussing challenges, this was the main focus for the volunteers. This suggests that, when implementing a system like CEBS, it is not just the structure of CEBS itself that needs to be in place, but also the infrastructures that CEBS depends on. A study done in Ghana on surveillance systems from the user perspective supports this finding (31). It also suggests that challenges with the support system detract focus from the actual system.

\section{Conclusion}

In this study, we have identified strengths and challenges with implementing and using a community based surveillance system, from the perspective of the volunteers, who are the main users. The main finding is that the volunteers experience the system as useful and SMS reporting as an easy, quick and reliable way of reporting, but only if external supports, such as mobile network and credit, are available. If not, challenges with transportation and expenses arise. When these external challenges are present, they become the main focus of the volunteers and it is difficult to assess other aspects of the system. Both high expectations and skepticism from the communities were reported, but this improved due to better information, positive results and that the volunteers were members of the communities and gained their trust. Training, guidelines and follow-up from supervisors, together with seeing results and having a role in helping their communities, were the main motivating factors.

\section{Strengths and Limitations with the study}

CEBS was implemented in Sierra Leone 2-3 months prior to the study period. Hence, the volunteers had limited experience, which influenced, at times, their responses. Some of the participants had never reported a case, which made it difficult for them to respond to questions about their own experiences with the reporting. At the same time, this also gives an important insight into perceptions the volunteers have in the initial phase of the system.

The inclusion criteria deliberately excluded volunteers working in the most hard-to-reach areas, which is an obvious limitation with potential implications for the data collected, as there could indeed be differences in the perceptions and experiences of these volunteers. At the same time, a diverse sample of volunteers was achieved, with all districts and 14 different chiefdoms represented.

The first author was, prior to the research, a member of the Red Cross staff supporting the system's implementation. The volunteers who participated in the study had not met the first author during the implementation, but some of them were aware of this. This could have influenced their responses, but the first author attempted to manage this by emphasizing the differences in these roles. This was also an important strength, enhancing the understanding of the data collected.

\section{Looking forward}

This study has generated insight into how a CBS system can be implemented and the aspects that need to be considered when planning and implementing such a project. It can hopefully be a resource for other projects. Although the study was conducted in a unique context with the Ebola outbreak, there are a number of matters related to project setup, use of volunteers and epidemic context for these findings to be relevant in other contexts.

As most of the resistance from the communities, in this study, was perceived and explained with respect to the fear associated with Ebola, it would be interesting to examine this topic of community response in another context.

Looking forward, there is also need for studies looking at the effectiveness, acceptance and user- friendliness of CBS projects that have been running for a longer time.

\section{Authorship and contributorship}

All authors contributed to the data analysis and manuscript drafting. TL, AM and CBM contributed to the project's conception and design. TL was responsible for the data collection and was supported in this task by a research assistant.

\section{Acknowledgment}

Thank you to the staff at the Sierra Leone Red Cross and the IFRC who made this study possible. Thank you to the volunteers who were willing to share their thoughts and experiences.

\section{Funding information}

This study was supported by the Norwegian Red Cross who funded travel expenses and expenses during the research period.

\section{Competing interest}

None 
Larsen TM (2017) Red Cross volunteers' experience with a mobile community event- based surveillance (CEBS) system in Sierra Leone during-and after the Ebola outbreak- A qualitative study

\section{References}

1. WHO (2016) National Passive Surveillance. Immunization, vaccines and biologicals, world health organization.

2. WHO (2016) Sentinel Surveillance. Immunization, vaccines and biologicals, world health organization.

3. IFRC (2012) Community early warning systems: guiding principles. IFRC p.1-84.

4. IFRC (2016) Community- based Surveillance Guide.

5. WHO (2014) Integrated Disease Surveillance and Response in the African Region. A guide for Establishing Community Based Surveillance.

6. Tomlinson M, Rotheram-Borus MJ, Swartz L, Tsai AC (2013) Scaling up mHealth: where is the evidence. PLoS Med 10: e1001382. [Crossref]

7. Brinkel J, Krämer A, Krumkamp R, May J, Fobil J (2014) Mobile phone-based mHealth approaches for public health surveillance in sub-Saharan Africa: a systematic review. Int J Environ Res Public Health 11: 11559-11582.

8. Tomlinson M, Solomon W, Singh Y, Doherty T, Chopra M, et al. (2009) The use of mobile phones as a data collection tool: a report from a household survey in South Africa. BMC Med Inform Decis Mak 9: 51. [Crossref]

9. Hartzler A, Wetter T (2014) Engaging Patients through Mobile Phones: Demonstrator Services, Success Factors, and Future Opportunities in Low and Middle-income Countries. Yearb Med Inform 9: 182-194.

10. Diwan V, Agnihotri D, Hulth A (2015) Collecting syndromic surveillance data by mobile phone in rural India: implementation and feasibility. Glob Health Action 1: 1-8.

11. WHO (2016) WHO statement on end of Ebola flare-up in Sierra Leone. Media center world health organization.

12. WHO (2015) Factors that contributed to undetected spread of the Ebola virus and impeded rapid containment. Emergencies preparedness, response, world health organization.

13. Van Bortel T, Basnayake A, Wurie F, Jambai M, Koroma AS, et al. (2016) Psychosocial effects of an Ebola outbreak at individual, community and international levels. Bull World Health Organ 94: 210-214. [Crossref]

14. Crowe S, Hertz D, Maenner M, Ratnayake R, Baker R, et al. (2015) A Plan for Community Event-Based Surveillance to Reduce Ebola Transmission - Sierra Leone, 2014-2015. Morbidity and Mortality Weekly Report (MMWR) 64: 70-73.

15. Lau MSY, Dalziel BD, Funk S, McClelland A, Tiffany A, et al. (2017) Spatial and temporal dynamics of superspreading events in the 2014-2015 West Africa Ebola epidemic. PNAS 9: 2337-2342.
16. ERC (2014) Standard operating procedure for Community- Event Based Surveillance for Ebola virus disease in Sierra Leone.

17. ERC (2015) Evaluation of the Functionality and Effectiveness of Community EventBased Surveillance (CEBS) in Sierra Leone.

18. Sierra Leone Red Cross and IFRC (2015) Project Description and Standard Operating Procedure for Community Event-Based Surveillance (CEBS) - Adapted from the Ebola Response Consortium's Standard Operating Procedure for Community Event-Based Surveillance for Ebola Virus Disease in Sierra Leone.

19. Magpi (2016) Advanced Mobile Data Collection- Anywhere, on Any Device.

20. SMSsync (2016) The free and open source SMS gateway for Android. Tableau. 2016.

21. Tableau. 2016. Tableau desktop. Analytics anyone can use.

22. CIA (2016) The World Factbook. Sierra Leone country information, Central Intelligence Agency.

23. Braun V, Clarke V (2006) Using thematic analysis in psychology. Qualitative Research in Psychology 3: 77-101.

24. Dil Y, Strachan D, Cairncross S, Korkor AS, Hill Z (2012) Motivations and Challenges of Community- Based Surveillance Volunteers in the Northern Region of Ghana. $J$ Community Health 37: 1192-1198.

25. Alfaro-Trujillo B, Valles-Medina AM, Vargas-Ojeda AC (2012) Profiles, Perceptions and Motivations of Community Health Workers of NGOs in a Border City of USMexico. J Community Health 37: 583.

26. Vareilles G, Pommier J, Kane S, Pictet G, Marchai B (2015) Understanding the motivation and performance of community health volunteers involved in the delivery of health programmes in Kampala, Uganda: a realist evaluation protocol. BMJ open 5: p.e 006752.

27. Nidaye SM, Quick L, Sanda O, Niandou S (2003) The value of community participation in disease surveillance: A case study from Niger. In Health Promotion International pp: 89-98.

28. Issah K, Nartey K, Amoah R, Bachan EG, Aleeba J, et al. (2015). Assessment of the usefulness of integrated disease surveillance and response on suspected ebola cases in the Brong Ahafo Region, Ghana . Infectious Diseases of Poverty, 20154:17.

29. Toyama, Y., Ota, M. and Beyene, B.B., (2015). Event-based surveillance in NorthWestern Ethiopia: experience and lessons learnt in the field. Western Pacific Surveillance and Response Journal, 6(3), pp.22-27

30. Adokiya, M.N. Awonoor- Williams, J.K., Beiersmann, C. and Muller, O. (2015). The integrated disease surveillance and response system in northern Ghana: challenges to the core and support functions. BMC Health Services Research, 15(1), p.288

Copyright: (C2017 Larsen TM. This is an open-access article distributed under the terms of the Creative Commons Attribution License, which permits unrestricted use, distribution, and reproduction in any medium, provided the original author and source are credited. 